\title{
Interventional Clinical Trials on Diabetic Peripheral Neuropathy: A Retrospective Analysis
}

\author{
Mengmeng Wang, ', Zepeng \\ Zhang, (D) ${ }^{2,3, *}$ Jia Mi, ${ }^{4}$ Guoqiang \\ Wang, (ID) ${ }^{4}$ Lulu Tian,' Yunyun \\ Zhao, (D) 'Xiaomin Li, ${ }^{2,5}$ Xiangyan \\ $\mathrm{Li}$, (iD) ${ }^{6}$ Xiuge Wang ${ }^{4}$ \\ 'College of Traditional Chinese Medicine, \\ Changchun University of Chinese Medicine, \\ Changchun, Jilin, People's Republic of China; \\ ${ }^{2}$ Research Center of Traditional Chinese \\ Medicine, The First Affiliated Hospital of \\ Changchun University of Chinese Medicine, \\ Changchun, Jilin, People's Republic of China; \\ ${ }^{3}$ College of Acupuncture and Tuina, \\ Changchun University of Chinese Medicine, \\ Changchun, Jilin, People's Republic of China; \\ ${ }^{4}$ Department of Endocrinology, The First \\ Affiliated Hospital of Changchun University of \\ Chinese Medicine, Changchun, Jilin, People's \\ Republic of China; ${ }^{5}$ Acupuncture and Massage \\ Center, The Third Affiliated Hospital of \\ Changchun University of Chinese Medicine, \\ Changchun, Jilin, People's Republic of China; \\ ${ }^{6}$ jilin Ginseng Academy, Key Laboratory of \\ Active Substances and Biological Mechanisms \\ of Ginseng Efficacy, Ministry of Education, Jilin \\ Provincial Key Laboratory of Bio- \\ Macromolecules of Chinese Medicine, \\ Changchun University of Chinese Medicine, \\ Changchun, Jilin, People's Republic of China
}

*These authors contributed equally to this work

Correspondence: Xiangyan Li jilin Ginseng Academy, Key Laboratory of Active Substances and Biological Mechanisms of Ginseng Efficacy, Ministry of Education, Jilin Provincial Key Laboratory of Bio-Macromolecules of Chinese Medicine, Changchun University of Chinese Medicine, Changchun, Jilin, People's Republic of China Tel +86 43I 86I77387

Email xiangyan_li1981@I63.com

Xiuge Wang

Department of Endocrinology, The First

Affiliated Hospital of Changchun University

of Chinese Medicine, Changchun, Jilin,

People's Republic of China

Tel +86 43I 86I77387

Email xiuge_w@163.com

\begin{abstract}
Aims/Introduction: Diabetic peripheral neuropathy (DPN) is the most common complication of diabetes. At present, there is no comprehensive summary of the clinical trials related to DPN. In this article, we summarized the basic characteristics of the interventional clinical trials pertaining to DPN to determine the current status of research in this field and the existing issues.
\end{abstract}

Materials and Methods: We searched the World Health Organization International Clinical Trial Registration Platform (ICTRP), PubMed and Web of Science for clinical trials from 2005 to April 2021 and extracted 149 registered and 459 published clinical trials on DPN. We summarized the characteristics of the clinical trials, including the source registration, recruitment status, stage, age group, allocation method, intervention, end point classification, funding source, and treatment.

Results: After excluding noninterventional and nontreatment trials, 149 registered clinical trials out of 292 records from 12 registration centers and 459 published articles were included in this study. Among the registered trials, $43 \%$ had been completed, and $34.4 \%$ had been published in peer-reviewed journals. Among these trials, more than half used random allocation and blinded placebo-controlled methodologies. A total of $40.3 \%$ of the trials were multicenter studies, $63.8 \%$ of the treatments were drug therapies, and the endpoint classifications of $49 \%$ were efficacy and safety. Of the 459 published interventional clinical trials on DPN, $69.7 \%$ of the trials used drug treatments; more than half were randomized, double-blind, placebo-controlled clinical trials; $94.1 \%$ had positive outcomes; $46.4 \%$ had a target size of 50 ; and $22.9 \%$ were multicenter.

Conclusion: This paper systematically summarizes the current status of interventional trials on DPN registered in the ICTRP and published clinical trials and provides a reference for the development of high-quality intervention strategies for DPN in the future.

Keywords: diabetic peripheral neuropathy, clinical interventional trials, ICTRP, clinical characteristics

\section{Introduction}

According to the International Diabetes Federation (IDF), the global prevalence of diabetes will rise to 578 million by 2030 and 700 million by $2045 .{ }^{1}$ Diabetic peripheral neuropathy (DPN) is the most common microvascular complication of diabetes, ${ }^{2}$ and $50 \%$ of diabetic patients eventually develop neuropathy during the course of their illness. ${ }^{3}$ DPN is defined as symptoms of peripheral nerve dysfunction after other reasons are excluded. ${ }^{4}$ Patients with DPN usually have numbness, tingling, pain or weakness that starts at the distal ends of the limbs, with the characteristic stocking-glove distribution, and progresses to the 
proximal ends. ${ }^{5}$ Many DPN patients suffer from chronic and severe neuropathic pain, which is difficult to treat and manage, seriously influencing their quality of life, imposing a heavy burden on them and increasing their medical costs. ${ }^{6}$ Currently, the treatment for DPN relies on prevention, blood sugar control, and pain and symptom control. ${ }^{7}$ Many patients do not receive effective treatment methods, and drug therapy is still the main treatment for DPN. ${ }^{8,9}$ The lack of efficacy and the occurrence of side effects of the drugs currently used for the prevention and treatment of DPN are serious clinical problems, and there is an urgent need to conduct in-depth research to develop new strategies. ${ }^{10}$

Clinical trials are pivotal in evaluating the efficacy of novel interventional therapies for different diseases. ${ }^{11}$ It is necessary to summarize the current status of clinical trials on DPN to improve awareness among researchers and doctors and promote current and future therapies and interventions. The World Health Organization (WHO) International Clinical Trials Registration Platform (ICTRP: http://www.who.int/ictrp) is a global database that aims to make information regarding all clinical trials involving human beings publicly available. $^{12}$ At present, there is no summary of the clinical studies on DPN registered in the ICTRP. We systematically summarized the characteristics of ongoing and completed interventional clinical trials on DPN with the aim of determining their current status and future research directions.

\section{Materials and Methods \\ Data Source and Search Strategy}

The preparation for this study occurred in three steps: (1) we obtained the registration records of clinical trials on DPN as of December 2020 in the WHO ICTRP Search Portal (http://apps.who.int/trialsearch) using the term "diabetic peripheral neuropathy"; (2) two investigators (MW and ZZ) used standardized strategies to manually search for peer-reviewed publications of completed clinical trials that involved searching for the publication in the ICTRP database, followed by searching in PubMed and Google Scholar using the NCT number or the short title of the trial and the name of the main researcher if the publication was not confirmed; and (3) the investigators reviewed the published clinical trials according to the preferred items for reporting systematic reviews and meta-analyses (PRISMA) guidelines. ${ }^{13}$ The databases were searched from the database inception to December 2020, and the language of publication was limited to English in PubMed and the Web of Science.

\section{Data Extraction and Selection}

All registered clinical trials were included regardless of language. The retrieved records from the ICTRP were exported to Microsoft Excel for filtering by title, abstract, and availability of the full-text article from March 31, 2005, to April 20, 2021 to exclude clinical trials on topics other than DPN. Then, we conducted an advanced search using the terms "diabetic peripheral neuropathy" and

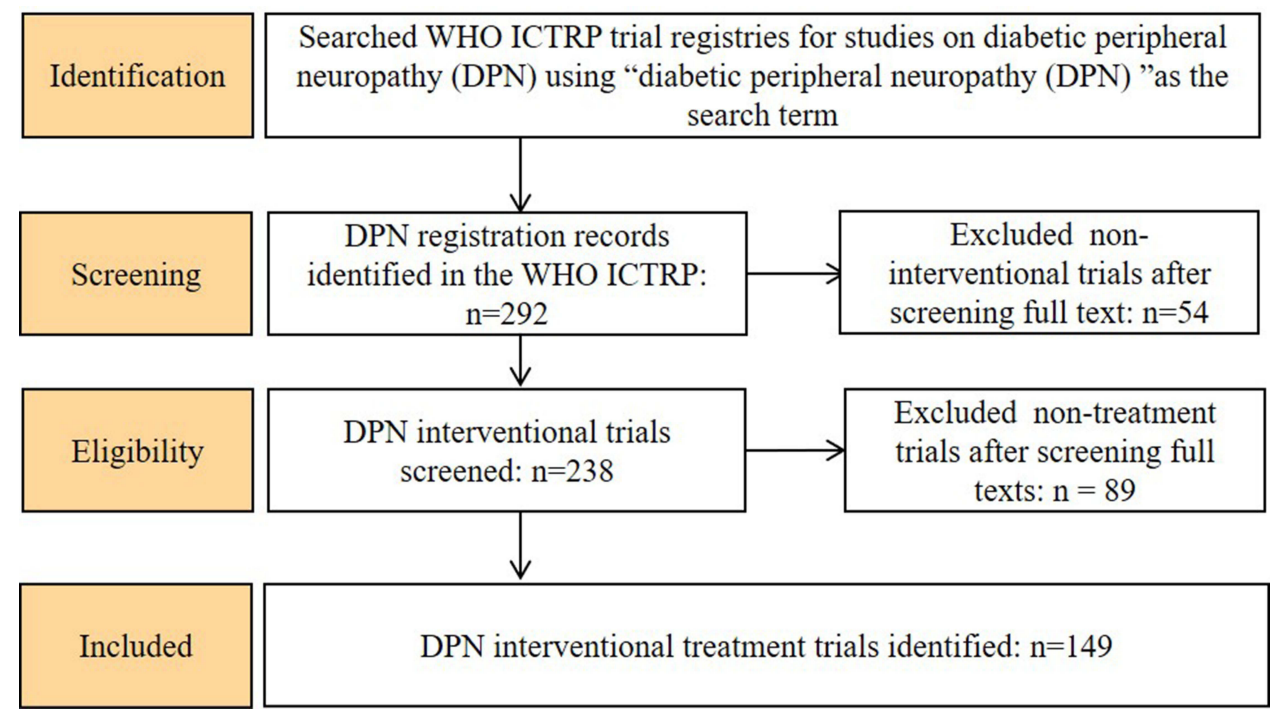

Figure I Flowchart of clinical trial selection from the WHO International Clinical Trials Registry Platform (ICTRP). 
"intervention" to obtain interventional or treatment trials on DPN for further analysis. Interventional clinical trials on DPN were identified and confirmed. Noninterventional or nontreatment trials were excluded after screening the full-text articles. The following data were extracted from the clinical trial records in the ICTRP database and entered into Excel: source register, recruitment status, trial phase, eligibility criteria (age group and sex), allocation, intervention model, number of arms, endpoint classification, placebo comparator, participating center, masking style, target size, treatment, condition, primary outcome, and secondary outcome. The type of funding for the clinical trials, such as whether the trials were funded by industry, was determined by the identification of the primary funding source. Before the data were extracted, the original registration website was visited to ensure that the data were current. The primary and secondary outcomes were classified and analyzed according to the items listed on the original website, and those that could not be classified were listed as "other". The publication was confirmed by matching the research characteristics outlined in the ICTRP database with the corresponding descriptions in the published manuscript. If multiple publications pertained to the same registered trial, the first article to report the main results was selected, and the others were excluded. We performed a systematic literature review and searched for published clinical trials on DPN from the date of the inception of the database to April 2021, excluding unlisted and unrelated studies. The first author (MW) used a predefined form to extract the following data, which were then entered into Microsoft Excel: title, year of publication, intervention duration (weeks), sample size, treatment, masking/blinding, randomized controlled trial design, placebo comparator, participating center and outcome.

\section{Discrepancies}

The data analysis was conducted by two researchers (MW, $\mathrm{ZZ}$ ), and any differences between the two researchers were resolved. If the two researchers could not reach an agreement, the final decision was made by a third researcher $(\mathrm{XL})$.

\section{Statistical Analyses}

Missing values were excluded from the analysis unless otherwise indicated. Descriptive statistics were used to describe the characteristics of the clinical trials. Categorical variables are expressed as frequencies and percentages. SAS software was used for all statistical analyses (version 9.3, SAS Institute Inc., Cary, NC, USA). GraphPad Prism 8.2.1 (GraphPad Software, San Diego, CA, USA) was used to construct the histograms and pie charts.

\section{Results}

\section{Basic Characteristics of Interventional Clinical Trials on DPN}

A total of 292 registered records of interventional clinical trials on DPN were retrieved from the ICTRP. Among these trials, 54 noninterventional trials were excluded: 50

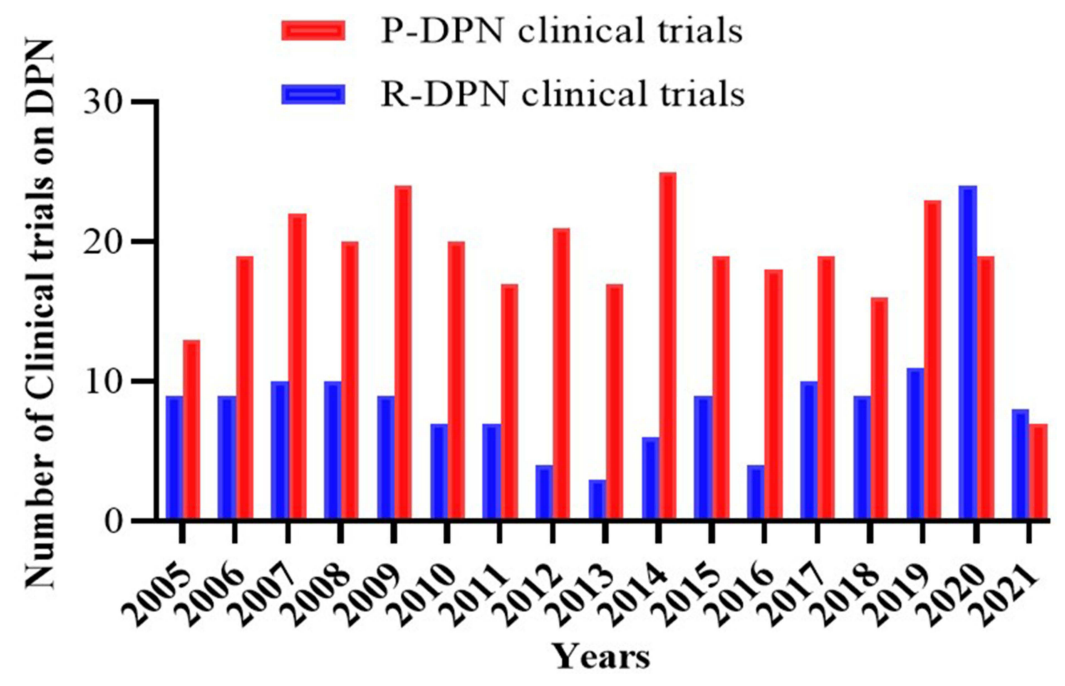

Figure 2 Number of clinical trials on DPN registered and published between 2005 and December 2020. R-clinical trials on DPN: registered clinical trials on DPN; P-clinical trials on DPN: published clinical trials on DPN. 
Table I Characteristics of Interventional Clinical Trials on DPN Registered in the ICTRP

\begin{tabular}{|c|c|c|c|}
\hline Characteristics & Category & $N=149$ & $\begin{array}{c}\text { Percentage of } \\
\text { Records (\%) }\end{array}$ \\
\hline \multirow{12}{*}{ Source register } & ANZCTR & 5 & 3.4 \\
\hline & ClinicalTrials.gov & 112 & 75.2 \\
\hline & CRIS & 1 & 0.7 \\
\hline & IRCT & 7 & 4.7 \\
\hline & ISRCTN & 3 & 2.0 \\
\hline & JPRN & 5 & 3.4 \\
\hline & PACTR & 2 & 1.3 \\
\hline & REBEC & I & 0.7 \\
\hline & ChiCTR & 4 & 2.7 \\
\hline & CTRI & 3 & 2.0 \\
\hline & EUCTR & I & 0.7 \\
\hline & TCTR & 5 & 3.4 \\
\hline \multirow{6}{*}{$\begin{array}{l}\text { Recruitment } \\
\text { status }\end{array}$} & Completed & 74 & 49.7 \\
\hline & Recruiting & 25 & 16.8 \\
\hline & Not recruiting & 29 & 19.5 \\
\hline & Terminated & 10 & 6.7 \\
\hline & Withdrawn & 5 & 3.4 \\
\hline & Unknown/Missing & 6 & 4.0 \\
\hline \multirow[t]{6}{*}{ Target size } & 0 to 50 & 47 & 31.5 \\
\hline & 51 to 100 & 24 & 16.1 \\
\hline & 101 to 200 & 30 & 20.1 \\
\hline & 201 to 500 & 41 & 27.5 \\
\hline & 501 to 1000 & 6 & 4.0 \\
\hline & Unknown/Missing & I & 0.7 \\
\hline \multirow{3}{*}{$\begin{array}{l}\text { Participating } \\
\text { center }\end{array}$} & Multicenter & 60 & 40.3 \\
\hline & Single center & 87 & 58.4 \\
\hline & Unknown/Missing & 2 & 1.3 \\
\hline \multirow[t]{4}{*}{ Age group } & Child/Adult/Senior & 2 & 1.3 \\
\hline & Adult & 15 & 10.1 \\
\hline & Adult/Senior & 130 & 87.2 \\
\hline & Unknown/Missing & 2 & 1.3 \\
\hline \multirow[t]{3}{*}{ Allocation } & Randomized & 116 & 77.9 \\
\hline & Non-randomized & 17 & 11.4 \\
\hline & Unknown/Missing & 16 & 10.7 \\
\hline \multirow[t]{6}{*}{ Number of arms } & I & 23 & 15.4 \\
\hline & 2 & 84 & 56.4 \\
\hline & 3 & 18 & 12.1 \\
\hline & 4 & 9 & 6.0 \\
\hline & $\geq 5$ & 9 & 6.0 \\
\hline & Unknown/Missing & 6 & 4.0 \\
\hline \multirow[t]{5}{*}{ Masking/Blinding } & Single blind & 8 & 5.4 \\
\hline & Double blind & 41 & 27.5 \\
\hline & Quadruple blind & 29 & 19.5 \\
\hline & Triple blind & 17 & 11.4 \\
\hline & Open label & 43 & 28.9 \\
\hline
\end{tabular}

(Continued)
Table I (Continued).

\begin{tabular}{|c|c|c|c|}
\hline Characteristics & Category & $N=149$ & $\begin{array}{c}\text { Percentage of } \\
\text { Records (\%) }\end{array}$ \\
\hline & Unknown/Missing & 11 & 7.4 \\
\hline Treatments & $\begin{array}{l}\text { Symptomatic } \\
\text { treatment of DPN } \\
\text { Pathogenetic } \\
\text { treatment } \\
\text { Other } \\
\text { pharmacologic } \\
\text { agents } \\
\text { Device } \\
\text { Exercise } \\
\text { Medical food } \\
\text { Genetic/Biological } \\
\text { therapy } \\
\text { Massage/ } \\
\text { Acupuncture } \\
\text { Revascularization } \\
\text { Hyperbaric } \\
\text { Oxygen Therapy } \\
\text { Lifestyle } \\
\text { Modification } \\
\text { Program }\end{array}$ & $\begin{array}{c}25 \\
9 \\
2 \\
8 \\
6 \\
1 \\
1 \\
2\end{array}$ & $\begin{array}{l}16.8 \\
6.0 \\
1.3 \\
5.4 \\
\\
4.0 \\
0.7 \\
0.7 \\
1.3\end{array}$ \\
\hline Condition & $\begin{array}{l}\text { Diabetic peripheral } \\
\text { neuropathy } \\
\text { Painful diabetic } \\
\text { neuropathy }\end{array}$ & $\begin{array}{l}94 \\
55\end{array}$ & $\begin{array}{l}63.1 \\
36.9\end{array}$ \\
\hline Phase & $\begin{array}{l}\text { Phase I/Phase } \\
\text { I-Phase II } \\
\text { Phase II } \\
\text { Phase II-Phase III } \\
\text { Phase III } \\
\text { Phase IV } \\
\text { Unknown/Missing }\end{array}$ & $\begin{array}{c}11 \\
46 \\
4 \\
23 \\
17 \\
48\end{array}$ & $\begin{array}{c}7.4 \\
\\
30.9 \\
2.7 \\
15.4 \\
11.4 \\
32.2\end{array}$ \\
\hline $\begin{array}{l}\text { Intervention } \\
\text { model }\end{array}$ & $\begin{array}{l}\text { Parallel assignment } \\
\text { Crossover } \\
\text { assignment } \\
\text { Sequential } \\
\text { assignment } \\
\text { Single group } \\
\text { assignment } \\
\text { Unknown/Missing }\end{array}$ & $\begin{array}{c}107 \\
10 \\
2 \\
19 \\
11\end{array}$ & $\begin{array}{c}71.8 \\
6.7 \\
1.3 \\
12.8 \\
7.4\end{array}$ \\
\hline $\begin{array}{l}\text { Endpoint } \\
\text { classification }\end{array}$ & $\begin{array}{l}\text { Efficacy } \\
\text { Efficacy and safety } \\
\text { Efficacy, safety and } \\
\text { pharmacokinetics } \\
\text { Others }\end{array}$ & $\begin{array}{c}52 \\
73 \\
3 \\
21\end{array}$ & $\begin{array}{c}34.9 \\
49.0 \\
2.0 \\
14.1\end{array}$ \\
\hline $\begin{array}{l}\text { Placebo } \\
\text { comparator }\end{array}$ & $\begin{array}{l}\text { Yes } \\
\text { No }\end{array}$ & $\begin{array}{l}65 \\
77\end{array}$ & $\begin{array}{l}43.6 \\
51.7\end{array}$ \\
\hline
\end{tabular}

(Continued) 
Table I (Continued).

\begin{tabular}{|c|c|c|c|}
\hline Characteristics & Category & $N=149$ & $\begin{array}{l}\text { Percentage of } \\
\text { Records (\%) }\end{array}$ \\
\hline & Unknown/Missing & 7 & 4.7 \\
\hline \multirow[t]{2}{*}{ Funding source } & Industry & 80 & 53.7 \\
\hline & Non-industry & 69 & 46.3 \\
\hline \multirow{2}{*}{$\begin{array}{l}\text { Results of } \\
\text { completed trials }\end{array}$} & Results available & 32 & 21.5 \\
\hline & No results available & 117 & 78.5 \\
\hline \multirow{2}{*}{$\begin{array}{l}\text { Primary } \\
\text { completed trials }\end{array}$} & Yes & 64 & 43.0 \\
\hline & No & 85 & 57.0 \\
\hline \multirow[t]{2}{*}{ Publication $^{\mathrm{a}}$} & Published & 22 & 29.7 \\
\hline & Not published & 52 & 70.3 \\
\hline \multirow[t]{6}{*}{ Location } & North America & 76 & 51.0 \\
\hline & Europe & 27 & 18.1 \\
\hline & Asia & 31 & 20.8 \\
\hline & South America & 4 & 2.7 \\
\hline & Africa & 9 & 6.0 \\
\hline & Latin America & 2 & 1.3 \\
\hline
\end{tabular}

Note: ${ }^{a}$ The total is the publication rate of completed trials.

observational trials, three factorial trials, and one diagnostic test trial. After screening the full texts of the remaining studies, 89 nontreatment trials were excluded, including 13 trials on supportive care, 67 trials with unknown/missing information, and nine other trials. Finally, 149 records of interventional clinical trials on DPN were included for further analysis (Figure 1). As shown in Figure 2, we found that these 149 trials were registered from 2005 to 2021, with approximately ten registrations every year. In 2020, the number of interventional clinical trials on DPN was two times that in the previous year. We found that Clinicaltrials.gov had the largest number and earliest submissions of interventional clinical trials on DPN, and all other registration platforms had fewer than 10 trials (Figure 2, Table 1).

With regard to recruitment, we found that $49.7 \%$ of the trials had completed recruitment. Approximately $68 \%$ of the clinical trials had a target size of fewer than 200, $31.5 \%$ of which had a sample size of less than 50 . More than half of the trials were single-center studies, and approximately $87.2 \%$ of the trials focused on adults/ elderly people. Most trials were randomized (77.9\%) and blinded (63.7\%), but approximately $51.7 \%$ of the trials did not use a placebo as a control. Trials in Phase II accounted for $30.9 \%$ of the total. Approximately $71.8 \%$ of the intervention models were parallel assignments. Drugs (63.8\%) were the most common interventional treatment, followed by devices (16.8\%). The endpoint classification in $49 \%$ of the trials was "efficacy and safety", followed by efficacy alone in $34.9 \%$; however, $78.5 \%$ of the trials had no available results. The most common funding source was industry $(53.7 \%)$, and nearly $51 \%$ of the trials were conducted in North America.

\section{Interventional Characteristics of I49 Clinical Trials on DPN}

Based on our analysis, there were nine types of interventions for the treatment of patients with DPN: drugs; devices; exercise; medical foods; genetic/biological therapies; revascularization; hyperbaric oxygen therapy; lifestyle modification programs; and massage/acupuncture. Of the 149 trials, three-fifths focused on drug interventions, followed by $19.4 \%$ focusing on supplementary alternative therapies and $16.8 \%$ focusing on devices, as shown in Figure 3A. In the 95 trials on drug therapies, $34.2 \%$ involved the symptomatic treatment of DPN; $17.5 \%$ involved pathogenetic treatments of DPN, and $12.2 \%$ were on other pharmacologic agents. These drugs included antidepressants, anticonvulsants, topical medications, opioid analgesics, nonopioid painkillers, vitamins and their derivatives, ion channel drugs, and traditional Chinese medicine (Figure 3B).

Anticonvulsant drugs, such as pregabalin, gabapentin, carbamazepine, and pregabalin, are most commonly used for the treatment of DPN. Moreover, some new drugs have emerged, such as the new nonopioid analgesic drugs SKL11197, SR419, and LX9211. In addition, clinical trials were performed to investigate the effects of certain drugs on the nourishment of nerves, such as vitamins and their derivatives, caper extracts, and green tea extracts. As shown in Figures 3C, 25 device intervention trials included management/therapy systems (3), wearable aids (3), laser treatments (4), electrical stimulation (13), peristaltic pulse pneumatic compression devices (1), and extracorporeal shock wave therapy (1). Among the 25 trials on devices, electrical stimulation as an auxiliary treatment measure accounted for half. An overview of these interventions in the 149 clinical trials on DPN is shown in Table 2 and Figure 3.

Primary and secondary outcomes were used to directly reflect the objectives of the clinical trials and assess the 
A

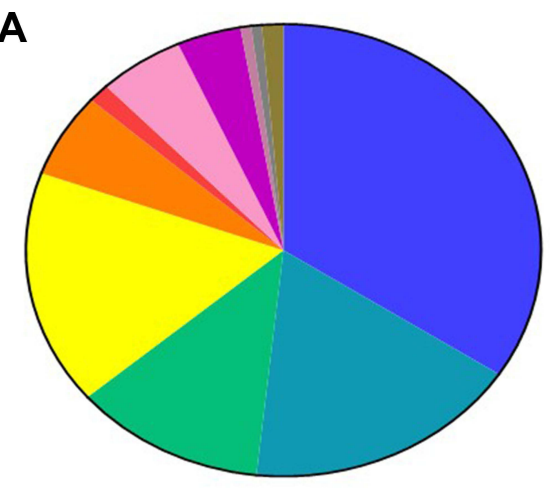

B

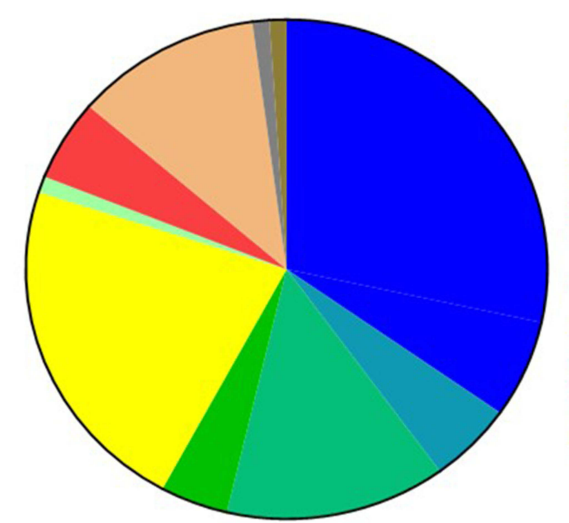

C

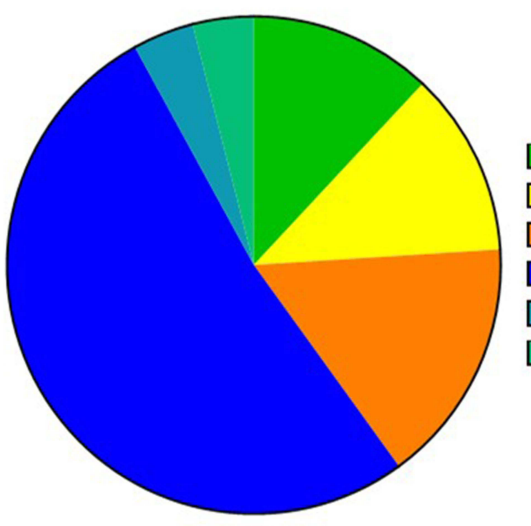

Symptomatic Treatment of DPN

Other pharmacologic agents

Device

Exercise

Medical food

Pathogenetic Treatments

Genetic/Biological therapy

Massage/Acupuncture

Revascularization

Hyperbaric Oxygen Therapy

Lifestyle Modification Program

Total $=25$

Management/Therapy System

Wearable aid

Laser treatment

Electrical stimulation

Peristaltic Pulse PCD

Extracorporeal shock wave therapy

Figure 3 Overview of the interventions in 149 clinical trials on DPN. (A) Intervention categories of 149 clinical trials on DPN; (B) Drug interventions in 92 clinical trials on DPN; (C) Device interventions in 25 clinical trials on DPN.

efficacy of the intervention or drug treatment. ${ }^{14}$ We summarized the primary and secondary outcomes of the 149 interventional clinical trials and found 313 primary outcomes and 725 secondary outcomes. The evolution of DPN pain was the most common evaluation index, accounting for $31.9 \%$ of the primary outcomes and
$22.3 \%$ of the secondary outcomes. Among the primary outcomes, clinical symptoms or signs accounted for $16.9 \%$, and neurophysiology accounted for $13.1 \%$. The categories and percentages of the primary outcomes and secondary outcomes in the 149 interventional trials are listed in Table 3. 
Table 2 Overview of the Interventions from 149 Clinical Trials on DPN

\begin{tabular}{|c|c|c|}
\hline Interventional Categories & $N=149$ & $\begin{array}{c}\text { Percentage of } \\
\text { Records (\%) }\end{array}$ \\
\hline \multicolumn{3}{|l|}{$\begin{array}{l}\text { Symptomatic Treatment of } \\
\text { DPN }\end{array}$} \\
\hline Anticonvulsants & 27 & 18.1 \\
\hline Antidepressants & 6 & 4.0 \\
\hline Opioids & 5 & 3.4 \\
\hline Non-opioid painkillers & 13 & 8.7 \\
\hline \multicolumn{3}{|l|}{ Pathogenetic Treatments } \\
\hline lon channel drugs & 4 & 2.7 \\
\hline Vitamin and its derivatives & 21 & 14.1 \\
\hline $\begin{array}{l}\text { Peripheral benzodiazepine } \\
\text { receptor (PBR) }\end{array}$ & I & 0.7 \\
\hline \multicolumn{3}{|l|}{ Other Pharmacologic Agents } \\
\hline Traditional Chinese medicine & 5 & 3.4 \\
\hline Topical medications & II & 7.4 \\
\hline MT-8554 & 1 & 0.7 \\
\hline TAK-128 & 1 & 0.7 \\
\hline \multicolumn{3}{|l|}{ Device } \\
\hline Management/Therapy system & 3 & 2.0 \\
\hline Wearable aid & 3 & 2.0 \\
\hline Laser treatment & 4 & 2.7 \\
\hline Electrical stimulation & 13 & 8.7 \\
\hline $\begin{array}{l}\text { Peristaltic pulse pneumatic } \\
\text { compression device }\end{array}$ & 1 & 0.7 \\
\hline $\begin{array}{l}\text { Extracorporeal shock wave } \\
\text { therapy }\end{array}$ & 1 & 0.7 \\
\hline Exercise & 9 & 6.0 \\
\hline Medical food & 2 & 1.3 \\
\hline Genetic/Biological therapy & 8 & 5.4 \\
\hline Massage/Acupuncture & 6 & 4.0 \\
\hline Revascularization & I & 0.7 \\
\hline Hyperbaric oxygen therapy & I & 0.7 \\
\hline $\begin{array}{l}\text { Lifestyle modification } \\
\text { program }\end{array}$ & 2 & 1.3 \\
\hline
\end{tabular}

\section{Characteristics of Interventional Trials According to Publication Status}

As of December 2020, 74 clinical trials on DPN had been completed. We found that only $29.7 \%$ of the trial outcomes were published in peer-reviewed journals, and $70.3 \%$ of the trial outcomes were unpublished. Drugs $(81.8 \%)$ were the most common interventional treatment in the published trials; among them,
Table 3 Primary Outcomes and Secondary Outcomes of 149 Interventional Trials on DPN

\begin{tabular}{|l|c|c|}
\hline Outcomes & $\mathbf{N}$ & $\begin{array}{c}\text { Percentage of } \\
\text { Records (\%) }\end{array}$ \\
\hline Primary outcomes (N=3 13) & & \\
Physical examinations & 11 & 3.5 \\
Risk of falls & 17 & 5.4 \\
Evaluation of diabetic peripheral & 100 & 31.9 \\
neuropathic pain & & \\
Neurophysiology & 41 & 13.1 \\
Clinical symptoms or signs & 53 & 16.9 \\
Safety/Tolerability/Efficacy & 13 & 4.2 \\
Pharmacokinetics & 7 & 2.2 \\
Laboratory tests & 26 & 8.3 \\
Epidermal nerve fiber density & 6 & 1.9 \\
Adverse events & 10 & 3.2 \\
Others & 29 & 9.3 \\
\hline Secondary outcomes (N=725) & & \\
Physical examinations & 10 & 1.4 \\
Evaluation of diabetic peripheral & 162 & 22.3 \\
neuropathic pain & & \\
Laboratory tests & 98 & 13.5 \\
Quality of life & 69 & 9.5 \\
Depression/anxiety score & 24 & 3.3 \\
Clinical symptoms or signs & 77 & 10.6 \\
Neurophysiology & 38 & 5.2 \\
Sleep interference score & 51 & 7.0 \\
Patient/Clinician evaluation & 39 & 5.4 \\
Risk of falls & 18 & 2.5 \\
Usage of rescue medication/Rescue & 12 & 1.7 \\
pain medication use & & 14.1 \\
Adverse events & & \\
Safety/Efficacy/Tolerability & & \\
Corneal confocal microscopy & 1.7 \\
Others & & \\
\hline
\end{tabular}

symptomatic treatment of DPN was used in $68.2 \%$ of trials, pathogenetic treatments in $13.6 \%$ and device treatment in $18.2 \%$. More than $81.8 \%$ of the published trials used a random allocation method, and $54.5 \%$ of the published trials used masking and a placebo comparator. All trials reported positive outcomes. Approximately $40.9 \%$ of the trials had an intervention duration of $8-12$ weeks. In total, $50 \%$ of published trials had a large sample size. Approximately $90.9 \%$ of the published trials were funded by industry sources, and $86.4 \%$ of the trials were multicenter studies. Multicenter trials increase the level of evidence and provide relatively more reliable conclusions (Table 4). 
Table 4 Characteristics of Interventional Trials According to Publication Status

\begin{tabular}{|c|c|c|}
\hline $\begin{array}{l}\text { Interventional } \\
\text { Categories }\end{array}$ & $\begin{array}{l}\text { Published } \\
(\mathbf{N}=\mathbf{2 2})\end{array}$ & $\begin{array}{c}\text { Percentage of } \\
\text { Records (\%) }\end{array}$ \\
\hline \multicolumn{3}{|l|}{ Treatment } \\
\hline Symptomatic & 15 & 68.2 \\
\hline \multicolumn{3}{|l|}{ Treatment of DPN } \\
\hline Pathogenetic & 3 & 13.6 \\
\hline \multicolumn{3}{|l|}{ Treatments } \\
\hline Device & 4 & 18.2 \\
\hline \multicolumn{3}{|l|}{ Allocation } \\
\hline Randomized & 18 & 81.8 \\
\hline Non-randomized & 4 & 18.2 \\
\hline \multicolumn{3}{|l|}{ Masking/Blinding } \\
\hline Single blind & 1 & 4.5 \\
\hline Double blind & 4 & 18.2 \\
\hline Quadruple blind & 4 & 18.2 \\
\hline Triple blind & 3 & 13.6 \\
\hline Open label & 10 & 45.5 \\
\hline \multicolumn{3}{|l|}{ Placebo comparator } \\
\hline Yes & 12 & 54.5 \\
\hline No & 10 & 45.5 \\
\hline \multicolumn{3}{|l|}{ Outcome } \\
\hline Positive & 22 & 100.0 \\
\hline \multicolumn{3}{|l|}{$\begin{array}{l}\text { Intervention time } \\
\text { (Weeks) }\end{array}$} \\
\hline$\leq 0$ to $\leq 4$ & 3 & 13.6 \\
\hline$>4$ to $\leq 8$ & 3 & 13.6 \\
\hline$>8$ to $\leq 12$ & 9 & 40.9 \\
\hline$>12$ to $\leq 16$ & 4 & 18.2 \\
\hline$>16$ & 3 & 13.6 \\
\hline \multicolumn{3}{|l|}{ Target size } \\
\hline 0 to 50 & 7 & 31.8 \\
\hline 51 to 100 & I & 4.5 \\
\hline 101 to 200 & 3 & 13.6 \\
\hline 201 to 500 & 9 & 40.9 \\
\hline 501 to 1000 & 2 & 9.1 \\
\hline \multicolumn{3}{|l|}{ Funding source } \\
\hline Industry & 20 & 90.9 \\
\hline Non-industry & 2 & 9.1 \\
\hline \multicolumn{3}{|l|}{ Participating center } \\
\hline Multicenter & 19 & 86.4 \\
\hline Single center & 3 & 13.6 \\
\hline
\end{tabular}

\section{Characteristics of Published Clinical Trials on DPN}

Because many registered trials do not update their results in a timely manner, we searched the published clinical trials to determine the progress that has been made in the field of DPN research. From 2005 to 2021, approximately 20 articles on clinical trials pertaining to DPN were published annually (Figure 2). We retrieved 2534 records of clinical trials on DN from the PubMed and Web of Science databases. We excluded 333 records not included in the databases, 202 duplicates, and 1540 irrelevant records. The final records were articles on pathogenesis and epidemiology (141), screening and diagnosis (137), diabetes mellitus and complications (646), peripheral neuralgia (243), diabetic foot (147), pharmacokinetics (5), noninterventional treatments (46), reviews (83), animal or in vitro studies (30), and other topics (62). Finally, 459 articles were included in the analysis (Figures 2 and 4).

Similar to the results of the analysis of registered clinical trials, the main interventions in the published articles were drugs, and more than half of the clinical trial designs were randomized, double-blind, and placebo controlled. The intervention time period was evenly distributed, but only $4.6 \%$ of the studies had an intervention duration lasting $12-16$ weeks. In total, $46.4 \%$ of the studies had target sizes smaller than 50 , and $77.1 \%$ of the articles reported single-center studies. Of the drug-related interventional trials, $28.5 \%$ focused on symptomatic treatment of DPN, and $18.1 \%$ focused on pathogenetic treatments. Among the device-related interventional trials, $58.5 \%$ investigated electrical stimulation. Peripheral nerve pain was used as the evaluation criterion (Tables 5 and 6, Figures 5 and 6).

\section{Discussion}

Through the ICTRP search portal, we identified recent clinical trials on DPN and completed the first summary and extensive investigation of the 149 registered clinical trials on DPN from 12 registries. Half of the clinical trials involving adult/senior patients did not use placebo, were conducted in a single center and were supported by industry funding. Most of the trials had small sample sizes $(<200)$, used parallel interventions and investigated different drugs. However, only approximately $22 \%$ of trials have available results, and $30 \%$ of those trials have published the results in a peer-reviewed publication.

Comprehensively analyzing the status of clinical trials on DPN is difficult if the ICTRP platform is not updated in a timely manner. Therefore, we searched 
clinical trials on DPN published in the PubMed and Web of Science databases. We found that the published clinical trials on DPN have the same characteristics as the registered clinical trials on DPN, but there are insufficient clinical trials on DPN, with approximately ten trials registered each year and approximately twenty articles published each year. We found that $6 \%$ of published interventional clinical trials on DPN reported negative results, which may be related to the small dose of the drug or the short duration of action, the selected subjects, and the complicated etiology of DPN. Therefore, a comprehensive clinical trial scheme for DPN is needed to provide a reference for future clinical research.

In this study, the target size of most registered and published clinical trials on DPN was less than 50, which may be related to the large proportion of Phase I to Phase II study trials among the registered trials. In studies involving vulnerable and underrepresented populations, early studies, and trials on rare diseases, a small sample size is reasonable. ${ }^{15,16}$ However, in most trials, a sample size that is too small will lead to inaccurate estimates in descriptive studies and inaccurate representations of statistical significance in analytical or comparative studies. ${ }^{17,18}$ Some drugs and treatments require a large sample size for investigation and verification. ${ }^{19-21}$ Therefore, it is necessary to include a large sample size to estimate the reliability and validity. In addition, single-center studies were common, and half of the clinical trials were concentrated in North America. Although the homogeneity of the samples is thereby ensured, these trials cannot meet the diversity and capacity requirements, cannot meet the regulatory requirements in multiple regions and do not reflect the clinical experience in different locations. ${ }^{22}$ Therefore, multicenter research can avoid the limitations of single research, and the conclusions can have wider generalizability and greater credibility. ${ }^{23}$

Our study found that $30 \%$ of clinical trials on DPN have been published in peer-reviewed journals, and more than half of these trials were randomized, blinded, placebo-controlled, and multicenter studies. Moreover, all published clinical trials reported positive results, which provides a scientific basis for the development of future clinical trials on DPN. However, $70 \%$ of the trials are still unpublished. The reasons they remain unpublished may be time constraints, resource limitations, rejection by journals, or bias against publishing negative results. These are important reasons for the low publication rate. Failure to publish is improper scientific

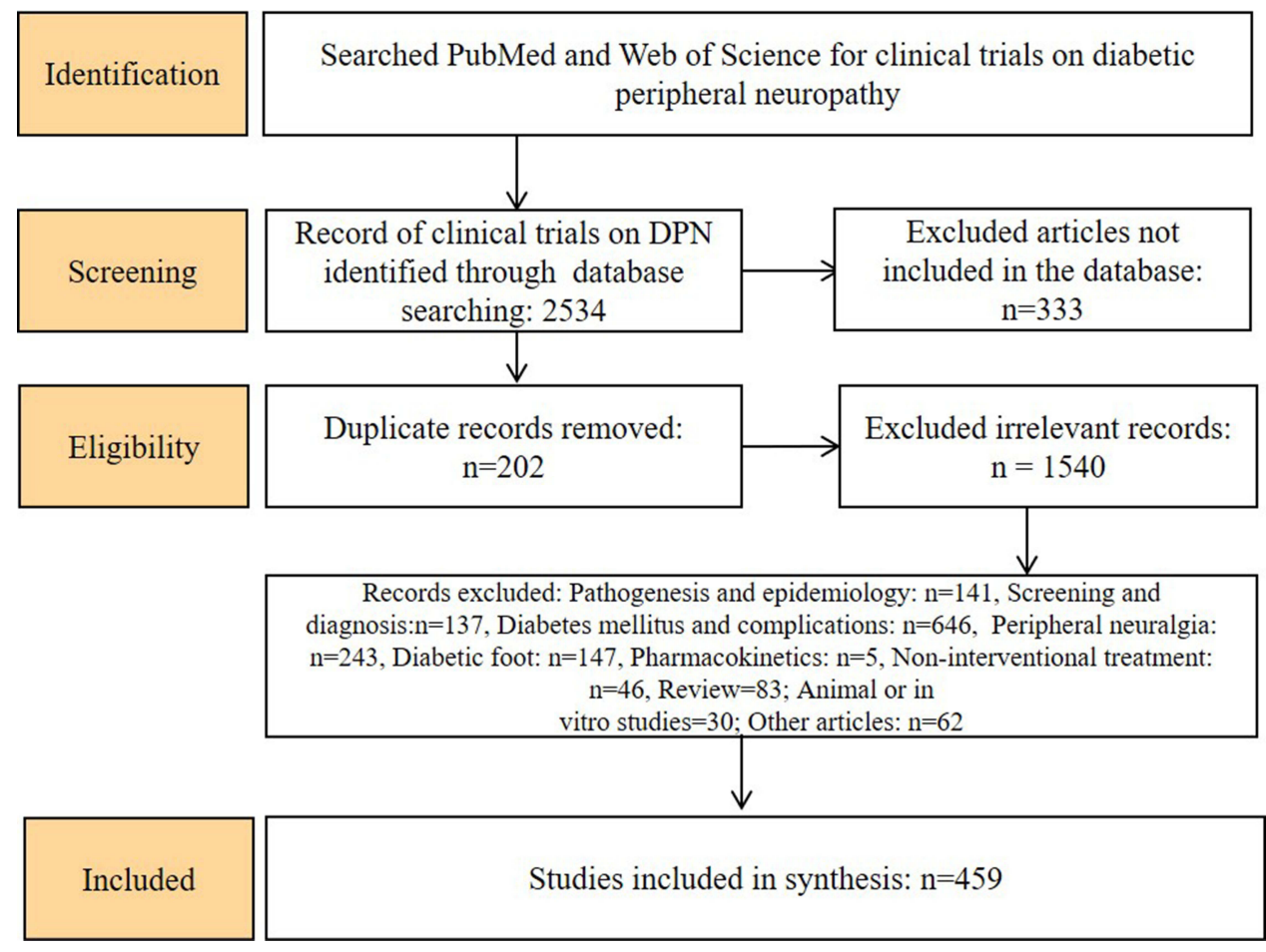

Figure 4 Flowchart of published clinical trial selection. 
Table 5 Characteristics of Published Interventional Clinical Trials on DPN

\begin{tabular}{|c|c|c|c|}
\hline Characteristics & Category & $N=459$ & $\begin{array}{c}\text { Percentage of } \\
\text { Records (\%) }\end{array}$ \\
\hline $\begin{array}{l}\text { Annual Number of } \\
\text { Articles Published }\end{array}$ & Years & & \\
\hline & $\begin{array}{l}<2005 \\
2005 \\
2006 \\
2007 \\
2008 \\
2009 \\
2010 \\
2011 \\
2012 \\
2013 \\
2014 \\
2015 \\
2016 \\
2017 \\
2018 \\
2019 \\
2020 \\
2021\end{array}$ & $\begin{array}{l}140 \\
13 \\
19 \\
22 \\
20 \\
24 \\
20 \\
17 \\
21 \\
17 \\
25 \\
19 \\
18 \\
19 \\
16 \\
23 \\
19 \\
7\end{array}$ & $\begin{array}{l}30.5 \\
2.8 \\
4.1 \\
4.8 \\
4.4 \\
5.2 \\
4.4 \\
3.7 \\
4.6 \\
3.7 \\
5.4 \\
4.1 \\
3.9 \\
4.1 \\
3.5 \\
5.0 \\
4.1 \\
1.5\end{array}$ \\
\hline Treatments & $\begin{array}{l}\text { Symptomatic } \\
\text { treatment of } \\
\text { DPN } \\
\text { Pathogenetic } \\
\text { treatments } \\
\text { Other } \\
\text { pharmacologic } \\
\text { agents } \\
\text { Device } \\
\text { Exercise } \\
\text { Medical food } \\
\text { Massage/ } \\
\text { Acupuncture } \\
\text { Genetic/ } \\
\text { Biological } \\
\text { therapy }\end{array}$ & $\begin{array}{c}|3| \\
83 \\
106 \\
\\
53 \\
40 \\
5 \\
24 \\
17\end{array}$ & $\begin{array}{l}28.5 \\
18.1 \\
23.1 \\
\\
11.5 \\
8.7 \\
1.1 \\
5.2 \\
3.7\end{array}$ \\
\hline Allocation & $\begin{array}{l}\text { Randomized } \\
\text { Non- } \\
\text { randomized }\end{array}$ & $\begin{array}{l}323 \\
136\end{array}$ & $\begin{array}{l}70.4 \\
29.6\end{array}$ \\
\hline Masking/Blinding & $\begin{array}{l}\text { Yes } \\
\text { No }\end{array}$ & $\begin{array}{l}272 \\
187\end{array}$ & $\begin{array}{l}59.3 \\
40.7\end{array}$ \\
\hline Placebo comparator & $\begin{array}{l}\text { Yes } \\
\text { No }\end{array}$ & $\begin{array}{l}253 \\
206\end{array}$ & $\begin{array}{l}55.1 \\
44.9\end{array}$ \\
\hline
\end{tabular}

(Continued)
Table 5 (Continued).

\begin{tabular}{|l|l|c|c|}
\hline Characteristics & Category & $\mathbf{N}=459$ & $\begin{array}{c}\text { Percentage of } \\
\text { Records (\%) }\end{array}$ \\
\hline Annual Number of & Years & & \\
\hline Outcome & & & \\
& Negative & 27 & 5.9 \\
& Positive & 432 & 94.1 \\
\hline Intervention time & & & \\
(Weeks) & & & \\
& 0 to $\leq 4$ & 131 & 28.5 \\
& $>4$ to $\leq 8$ & 82 & 17.9 \\
& $>8$ to $\leq 12$ & 102 & 22.2 \\
& $>12$ to $\leq 16$ & 21 & 4.6 \\
& $>16$ & 123 & 26.8 \\
\hline Target size & & & \\
& 0 to 50 & 213 & 46.4 \\
& 51 to 100 & 102 & 22.2 \\
& 101 to 200 & 48 & 10.5 \\
& 201 to 500 & 64 & 13.9 \\
& 501 to 1000 & 19 & 4.1 \\
& $>1000$ & 13 & 2.8 \\
\hline Participating center & & & \\
& Multicenter & 105 & 22.9 \\
& Single center & 354 & 77.1 \\
\hline
\end{tabular}

behavior, as unpublished evidence is not available as a reference for the scientific community and clinicians. $^{24}$ Therefore, the results of completed trials should be actively published, ensuring that they can serve as a reference for future clinical trials and thereby avoiding wasting resources by unnecessarily repeating research.

Neuropathic pain affects approximately one-third of patients with diabetes, ${ }^{25,26}$ and DPN is a key factor in the development of diabetic foot ulcers, the most common cause of amputation. ${ }^{14}$ With the discovery of risk factors for DPN and a deepening understanding of the pathogenesis, ${ }^{27}$ many researchers have developed effective treatments for DPN. Clinical trials have focused on various treatment strategies for specific pathogeneses of DPN. However, the treatment methods in these studies are only available in a few countries/regions. ${ }^{27,28}$ Our research found that $17 \%$ of DPN clinical trials and $18 \%$ of published DPN clinical trials were for pathogenetic treatments. However, there is currently no treatment that 
Table 6 Overview of Interventions in 452 Clinical Trials on DPN

\begin{tabular}{|c|c|c|}
\hline Interventional Categories & $N=459$ & $\begin{array}{c}\text { Percentage of } \\
\text { Records (\%) }\end{array}$ \\
\hline \multicolumn{3}{|l|}{$\begin{array}{l}\text { Symptomatic Treatment of } \\
\text { DPN }\end{array}$} \\
\hline Anticonvulsants & 71 & 15.5 \\
\hline Antidepressants & 40 & 8.7 \\
\hline Opioids & 20 & 4.4 \\
\hline \multicolumn{3}{|l|}{ Pathogenetic Treatments } \\
\hline Aldose reductase inhibitors & 46 & 10.0 \\
\hline Vitamin and its derivatives & 19 & 4.1 \\
\hline Antioxidative agent & 18 & 3.9 \\
\hline \multirow{2}{*}{\multicolumn{3}{|c|}{$\begin{array}{l}\text { Other Pharmacologic } \\
\text { Agents }\end{array}$}} \\
\hline & & \\
\hline Topical Medications & 33 & 7.2 \\
\hline Vasodilator & 13 & 2.8 \\
\hline Other pharmacologic agents & 60 & 13.1 \\
\hline \multicolumn{3}{|l|}{ Device } \\
\hline Management/Therapy system & I & 0.2 \\
\hline Wearable aid & 9 & 2.0 \\
\hline Laser treatment & 3 & 0.7 \\
\hline Electrical stimulation & 31 & 6.8 \\
\hline $\begin{array}{l}\text { Monochromatic infrared } \\
\text { energy (MIRE) }\end{array}$ & 9 & 2.0 \\
\hline Exercise & 40 & 8.7 \\
\hline Medical food & 5 & 1.1 \\
\hline Massage/Acupuncture & 24 & 5.2 \\
\hline Genetic/Biological therapy & 17 & 3.7 \\
\hline
\end{tabular}

can prevent or reverse DPN; instead, treatment is limited to pain management. ${ }^{27,28}$ In addition, our results revealed that $34 \%$ of DPN clinical trials and $29 \%$ of published DPN clinical trials were for symptomatic treatment. In our study, drugs were the most commonly used intervention, followed by devices, and then drug studies focused on anticonvulsants, aldose reductase inhibitors, and antidepressants. However, drugs for neuropathic pain are associated with many side effects, such as nausea, dizziness, dry mouth, and weight gain, which occur in $40 \%$ of the population and are dosedependent. $^{29}$ Due to changes in the pathogenesis of DPN, the efficacy of ARIs may be limited. ${ }^{30}$ Although many ARIs have been successfully developed in in vivo and in vitro experiments, they have failed in most clinical trials due to adverse drug reactions and inadequate efficacy. $^{31}$
The safety and effectiveness of medical products need to be reviewed before they are used in the general population, which is supervised and implemented by the Food and Drug Administration (FDA). Drugs can be approved by the FDA in a variety of ways. ${ }^{32}$ FDA approval of a new drug is associated with an increase in the publication of clinical trial registrations and reports of results for the drug. ${ }^{33}$ However, the failure of new DPN drugs approved by the FDA may be related to the low annual registration rate of clinical trials, the delay in reporting test results, the low publication rate of articles or the stage of the clinical trial. Therefore, in future research, we should develop drugs based on the pathogenesis of DPN and reduce side effects. External treatments of DPN include topical drug therapies and device treatments. For patients who cannot tolerate oral medications, topical medication is a good choice. The most common local analgesics are lidocaine, capsaicin, and amitriptyline. ${ }^{29}$ Lidocaine patches can improve the quality of life of patients with DPN, and their efficacy is equivalent to that of pregabalin. $^{34}$ Capsaicin can reduce pain and improve sleep quality in patients with DPN. ${ }^{35}$ Our study found that 11 clinical trials investigated topical drugs as interventions, and $7 \%$ of the published clinical trials involved topical drug therapies. Topical drug therapies are safe and effective and are a valuable choice for the treatment of DPN. Due to oral drug intolerance and the high proportion of elderly patients, the development of topical drugs has great potential. ${ }^{10,36}$

Research on device treatments has shown that highfrequency spinal cord stimulation is a safe and effective means of providing analgesia, and pulsed electromagnetic fields can regulate neuropathic pain and nerve impulses. $^{37}$ Plantar electrical stimulation can improve the ankle brachial index and enhance motor ability and plantar sensation in patients with DPN. ${ }^{21}$ In this study, we found that electrical stimulation device studies accounted for half of the studies on devices. Electrical stimulation has no contraindications or side effects and may be an effective alternative and adjuvant therapy for DPN. $^{38}$

\section{Conclusions and Future Perspectives}

This report is the first summary of the registration of DPN clinical trials in the ICTRP Registration Platform and the 
A

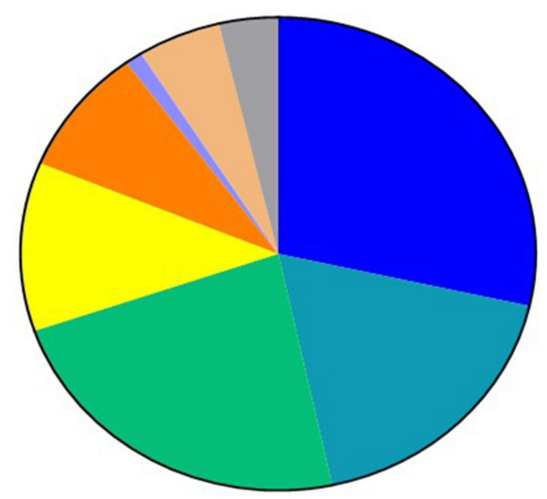

Total $=\mathbf{4 5 9}$

B

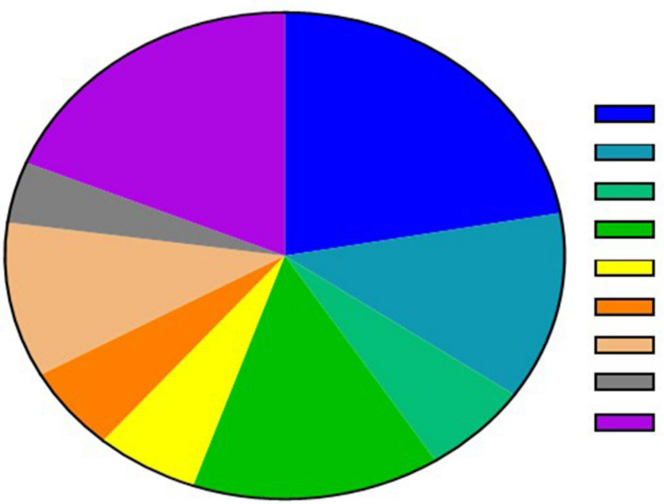

Total $=320$

C

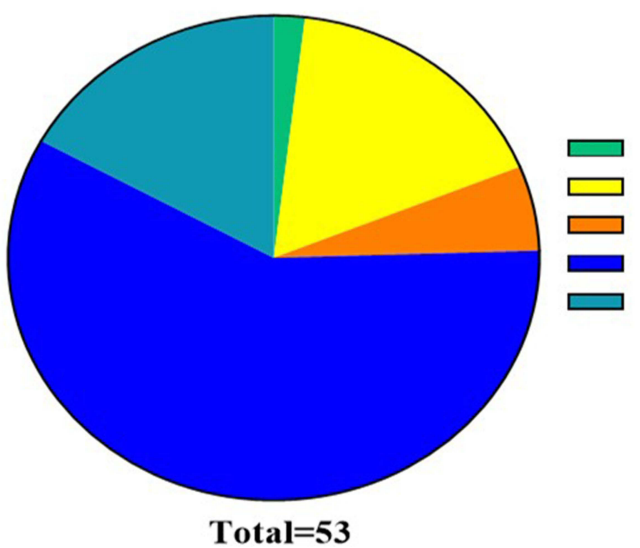

Symptomatic Treatment of DPN

Pathogenetic Treatments

Other pharmacologic agents

Device

Exercise

$\square$ Medical food

$\square$ Massage/Acupuncture

$\square$ Genetic/Biological therapy
Anticonvulsants

Antidepressants

Opioids

Aldose reductase inhibitors

Aldose reductase inhibitors

Antioxidative agent

Topical Medications

Vasodilator

Other pharmacologic agents
Management/Therapy system

Wearable aid

Laser treatment

Electrical stimulation

Monochromatic infrared energy

Figure 5 Intervention characteristics in 452 published clinical trials on DPN. (A) Intervention categories in 452 published clinical trials on DPN; (B) drug interventions in 315 published clinical trials on DPN; (C) device interventions in 52 published clinical trials on DPN.

current situation of DPN clinical studies. We found that the sample size of most DPN clinical trials was usually small and conducted in a single center. In addition, the clinical registration information and results were not updated in a timely manner. Most clinical trials have focused on drug interventions, and symptomatic treatment accounts for approximately $30 \%$ of interventional DPN clinical trials. However, given the lack of understanding of the pathogenesis of DPN, the treatment of the pathogenesis was the focus in only approximately $17.5 \%$ of clinical trials. The main evaluation indicators at this stage were pain or clinical symptoms.

However, this summary for DPN clinical trials had several limitations. First, we cannot guarantee the absolute reliability of the results. We only provide an overview of the characteristics of the clinical trials on DPN. We did not have access to the complete trial plans and data, and we were unable to evaluate the shortcomings and advantages 


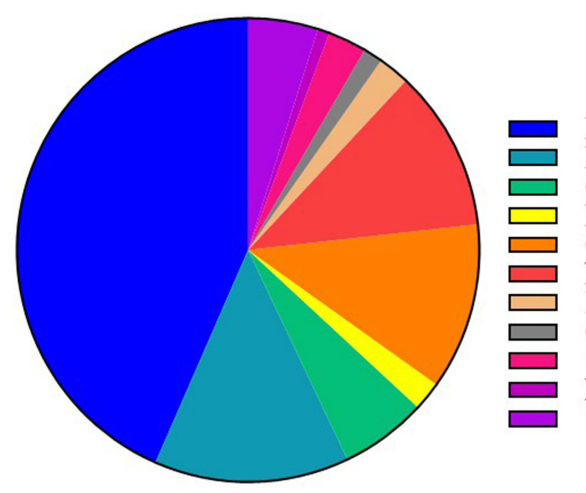

Total=594
Evaluation of Diabetic Peripheral Neuropathic Pain

Laboratory tests

Quality of life

Emotional Functioning

Clinical symptoms or signs

Neurophysiology

Intraepidermal nerve fiber (IENF) density

Other

Safety/Efficacy/Tolerability

Balance Symptoms

Sleep Interference Score

Figure 6 Outcomes in 586 published clinical trials on DPN

of the trials. Second, we only retrieved publications from 22 trials. There may be more clinical trials to be published, but we did not contact the main investigators to verify the situation. Third, we only identified published clinical trials on DPN in the PubMed and Web of Science databases, and we may therefore have missed some published clinical trials.

In the future, we hope that more multicenter, largesample, placebo-controlled, randomized DPN clinical trials would provide high-quality clinical evidence. In addition to pain scores, comprehensive outcome indicators such as quality of life, quality of sleep, and psychological status should be considered as secondary outcomes. Collectively, this study could provide a reference and new insights for future DPN interventional trials.

\section{Acknowledgments}

We acknowledge the National Key Research and Development Program of China (2019YFC1709904) and the Science and Technology Development Plan Project of Jilin Province (20190201145JC and 20190101010JH).

\section{Disclosure}

The authors declare that they have no conflicts of interest for this work.

\section{References}

1. Saeedi P, Petersohn I, Salpea P, et al. Global and regional diabetes prevalence estimates for 2019 and projections for 2030 and 2045: results from the international diabetes federation diabetes atlas, 9 (th) edition. Diabetes Res Clin Pract. 2019;157:107843. doi:10.1016/j. diabres.2019.107843

2. Kosiborod M, Gomes MB, Nicolucci A, et al. Vascular complications in patients with type 2 diabetes: prevalence and associated factors in 38 countries (the DISCOVER Study program). Cardiovasc Diabetol. 2018;17(1):150. doi:10.1186/s12933-018-0787-8
3. Iqbal Z, Azmi S, Yadav R, et al. Diabetic peripheral neuropathy: epidemiology, diagnosis, and pharmacotherapy. Clin Ther. 2018;40 (6):828-849. doi:10.1016/j.clinthera.2018.04.001

4. Boulton AJ. Guidelines for diagnosis and outpatient management of diabetic peripheral neuropathy. European association for the study of diabetes, neurodiab. Diabetes Metab. 1998;24(Suppl 3):55-65.

5. Callaghan BC, Price RS, Feldman EL. Distal symmetric polyneuropathy in 2020. JAMA. 2020;324(1):90-91. doi:10.1001/jama.2020.0700

6. Bonhof GJ, Herder C, Strom A, Papanas N, Roden M, Ziegler D. Emerging biomarkers, tools, and treatments for diabetic polyneuropathy. Endocr Rev. 2019;40(1):153-192.

7. Pop-Busui R, Boulton AJ, Feldman EL, et al. Diabetic neuropathy: a position statement by the American diabetes association. Diabetes Care. 2017;40(1):136-154. doi:10.2337/dc16-2042

8. Khdour MR. Treatment of diabetic peripheral neuropathy: a review. J Pharm Pharmacol. 2020;72(7):863-872. doi:10.1111/jphp.13241

9. Malik RA, Veves A, Tesfaye S, et al. Small fibre neuropathy: role in the diagnosis of diabetic sensorimotor polyneuropathy. Diabetes Metab Res Rev. 2011;27(7):678-684. doi:10.1002/dmrr.1222

10. Kaur S, Pandhi P, Dutta P. Painful diabetic neuropathy: an update. Ann Neurosci. 2011;18(4):168-175. doi:10.5214/ans.0972.7531.11 18409

11. Tesfaye S, Selvarajah D. Advances in the epidemiology, pathogenesis and management of diabetic peripheral neuropathy. Diabetes Metab Res Rev. 2012;28(Suppl 1):8-14. doi:10.1002/dmrr.2239

12. Shillo P, Sloan G, Greig M, et al. Painful and painless diabetic neuropathies: what is the difference? Curr Diab Rep. 2019;19 (6):32. doi:10.1007/s11892-019-1150-5

13. Page MJ, Moher D, Bossuyt PM, et al. PRISMA 2020 explanation and elaboration: updated guidance and exemplars for reporting systematic reviews. BMJ. 2021;372:n160.

14. Selvarajah D, Kar D, Khunti K, et al. Diabetic peripheral neuropathy: advances in diagnosis and strategies for screening and early intervention. Lancet Diabetes Endocrinol. 2019;7(12):938-948. doi:10.1016/S2213-8587(19)30081-6

15. He Y, Yang J, Lv Y, et al. A review of ginseng clinical trials registered in the WHO international clinical trials registry platform. Biomed Res Int. 2018;2018:1843142. doi:10.1155/2018/1843142

16. Etz KE, Arroyo JA. Small sample research: considerations beyond statistical power. Prev Sci. 2015;16(7):1033-1036. doi:10.1007/ s11121-015-0585-4

17. Weber EJ, Hoo ZH. Why sample size estimates? Emerg Med J. 2018;35(12):755-756.

18. Noordzij M, Tripepi G, Dekker FW, Zoccali C, Tanck MW, Jager KJ. Sample size calculations: basic principles and common pitfalls. Nephrol Dial Transplant. 2010;25(5):1388-1393. doi:10.1093/ndt/ gfp 732 
19. Jann S, Fazio R, Cocito D, et al. High-dose intravenous immunoglobulin is effective in painful diabetic polyneuropathy resistant to conventional treatments. results of a double-blind, randomized, placebo-controlled, multicenter trial. Pain Med. 2020;21 (3):576-585. doi:10.1093/pm/pnz331

20. Bramson C, Herrmann DN, Carey W, et al. Exploring the role of tanezumab as a novel treatment for the relief of neuropathic pain. Pain Med. 2015;16(6):1163-1176. doi:10.1111/pme.12677

21. Najafi B, Talal TK, Grewal GS, Menzies R, Armstrong DG, Lavery LA. Using plantar electrical stimulation to improve postural balance and plantar sensation among patients with diabetic peripheral neuropathy: a Randomized Double Blinded Study. J Diabetes Sci Technol. 2017;11(4):693-701. doi:10.1177/193229 6817695338

22. Didangelos T, Karlafti E, Kotzakioulafi E, et al. Efficacy and safety of the combination of superoxide dismutase, alpha lipoic acid, vitamin B12, and carnitine for 12 months in patients with diabetic neuropathy. Nutrients. 2020;12(11):3254. doi:10.3390/nu12113254

23. Chung KC, Song JW; Group WS. A guide to organizing a multicenter clinical trial. Plast Reconstr Surg. 2010;126(2):515-523. doi:10.1097/PRS.0b013e3181df64fa

24. Hopewell S, Loudon K, Clarke MJ, Oxman AD, Dickersin K. Publication bias in clinical trials due to statistical significance or direction of trial results. Cochrane Database Syst Rev. 2009;(1): MR000006. doi:10.1002/14651858.MR000006.pub3

25. Liampas A, Rekatsina M, Vadalouca A, Paladini A, Varrassi G, Zis P. Pharmacological management of painful peripheral neuropathies: a systematic review. Pain Ther. 2020:1-4.

26. Peltier A, Goutman SA, Callaghan BC. Painful diabetic neuropathy. BMJ. 2014;348(may06 1):g1799. doi:10.1136/bmj.g1799

27. Tang HY, Jiang AJ, Ma JL, Wang FJ, Shen GM. Understanding the signaling pathways related to the mechanism and treatment of diabetic peripheral neuropathy. Endocrinology. 2019;160(9):2119-2127. doi:10.1210/en.2019-00311

28. Malik RA. Why are there no good treatments for diabetic neuropathy? Lancet Diabetes Endocrinol. 2014;2(8):607-609. doi:10.1016/S2213-8587(14)70067-1

29. Argoff CE. Topical analgesics in the management of acute and chronic pain. Mayo Clin Proc. 2013;88(2):195-205. doi:10.1016/j. mayocp.2012.11.015
30. Mizukami H, Osonoi S. Pathogenesis and molecular treatment strategies of diabetic neuropathy collateral glucose-utilizing pathways in diabetic polyneuropathy. Int J Mol Sci. 2020;22(1):94. doi:10.3390/ ijms22010094

31. Niimi N, Yako H, Takaku S, Chung SK, Sango K. Aldose reductase and the polyol pathway in schwann cells: old and new problems. Int J Mol Sci. 2021;22(3):1031. doi:10.3390/ijms22031031

32. Eckert JC. Characteristics of trials associated with drugs approved by the food and drug administration in 2015 and 2016. Med Care. 2020;58(3):194-198. doi:10.1097/MLR.0000000000001254

33. Phillips AT, Desai NR, Krumholz HM, Zou CX, Miller JE, Ross JS. Association of the FDA amendment act with trial registration, publication, and outcome reporting. Trials. 2017;18(1):333. doi:10.1186/ s13063-017-2068-3

34. Baron R, Mayoral V, Leijon G, Binder A, Steigerwald I, Serpell M. $5 \%$ Lidocaine medicated plaster versus pregabalin in post-herpetic neuralgia and diabetic polyneuropathy: an open-label, non-inferiority two-stage RCT study. Curr Med Res Opin. 2009;25(7):1663-1676. doi:10.1185/03007990903047880

35. Simpson DM, Robinson-Papp J, Van J, et al. Capsaicin 8\% patch in painful diabetic peripheral neuropathy: a Randomized, Double-Blind, Placebo-Controlled Study. J Pain. 2017;18(1):42-53. doi:10.1016/j. jpain.2016.09.008

36. Baron R, Allegri M, Correa-Illanes G, et al. The 5\% lidocaine-medicated plaster: its inclusion in international treatment guidelines for treating localized neuropathic pain, and clinical evidence supporting its use. Pain Ther. 2016;5(2):149-169. doi:10.1007/ s40122-016-0060-3

37. Mekhail NA, Argoff CE, Taylor RS, et al. High-frequency spinal cord stimulation at $10 \mathrm{kHz}$ for the treatment of painful diabetic neuropathy: design of a multicenter, randomized controlled trial (SENZA-PDN). Trials. 2020;21(1):87. doi:10.1186/s13063-0194007-y

38. Thakral G, Kim PJ, LaFontaine J, Menzies R, Najafi B, Lavery LA. Electrical stimulation as an adjunctive treatment of painful and sensory diabetic neuropathy. $J$ Diabetes Sci Technol. 2013;7 (5):1202-1209. doi:10.1177/193229681300700510
Journal of Pain Research

\section{Publish your work in this journal}

The Journal of Pain Research is an international, peer reviewed, open access, online journal that welcomes laboratory and clinical findings in the fields of pain research and the prevention and management of pain. Original research, reviews, symposium reports, hypothesis formation and commentaries are all considered for publication. The manuscript management system is completely online and includes a very quick and fair peer-review system, which is all easy to use. Visit http:// www.dovepress.com/testimonials.php to read real quotes from published authors. 